\title{
Type III/Type IV Giant Para-Oesophageal Herniae: Our Technique of Gastropexy with Biological Prosthesis
}

\author{
Kassem Alubaidi' ${ }^{1}$, Ashish Kiran Shrestha ${ }^{2}$, Meera Joshi ${ }^{3}$, Sanjoy Basu ${ }^{1}$ \\ ${ }^{1}$ Department of General Surgery, William Harvey Hospital, Kent, UK \\ ${ }^{2}$ Department of Surgery and Cancer, Imperial College, London, UK \\ ${ }^{3}$ Surgical Registrar, WHH, Kent, UK \\ Email: sanjoy.basu@ekht.nhs.uk, Ashish339@yahoo.com
}

Received 18 March 2016; accepted 8 May 2016; published 11 May 2016

Copyright (C) 2016 by authors and Scientific Research Publishing Inc.

This work is licensed under the Creative Commons Attribution International License (CC BY). http://creativecommons.org/licenses/by/4.0/

c) (i) Open Access

\begin{abstract}
Objective: To present our technique of laparoscopic repair of giant para-oesophageal hernia with biological prosthesis (porcine dermis). Method: Our technique involves creating a pneumoperitoneum with standard port placement for anti-reflux surgery, mediastinal sac dissection and excision, crura-plasty, tension free placement of the biological prosthesis for hiatal reinforcement, fundoplication and gastropexy. Conclusion: Our technique of laparoscopic repair of giant paraoesophageal hernia with biological mesh is feasible and safe with acceptable morbidity and outcome.
\end{abstract}

\section{Keywords}

Giant Para-Oesophageal Herniae, Hiatal Defect, Biological Mesh, Gastropexy

\section{Introduction}

Giant paraoesophageal hernia that accounts for $5 \%$ of all hiatus hernia is defined as $30 \%-50 \%$ displacement of the stomach above the diaphragm (Figure 1) [1]-[6]. Various techniques from endoscopic reduction to percutaneous gastrostomy have been advocated but the gold standard intervention remains either an open or a laparoscopic surgical repair [6] through either a primary suture repair or a tension free hiatal mesh reinforcement [1]-[3] [6].

We have an 8-year experience at repairing GPEH (Type III-IV) laparoscopically with biological prosthesis (non-cross linked porcine dermis) and describe here our technique of hiatal reconstruction for these patients.

How to cite this paper: Alubaidi, K., Shrestha, A.K., Joshi, M. and Basu, S. (2016) Type III/Type IV Giant Para-Oesophageal Herniae: Our Technique of Gastropexy with Biological Prosthesis. Surgical Science, 7, 226-229. 


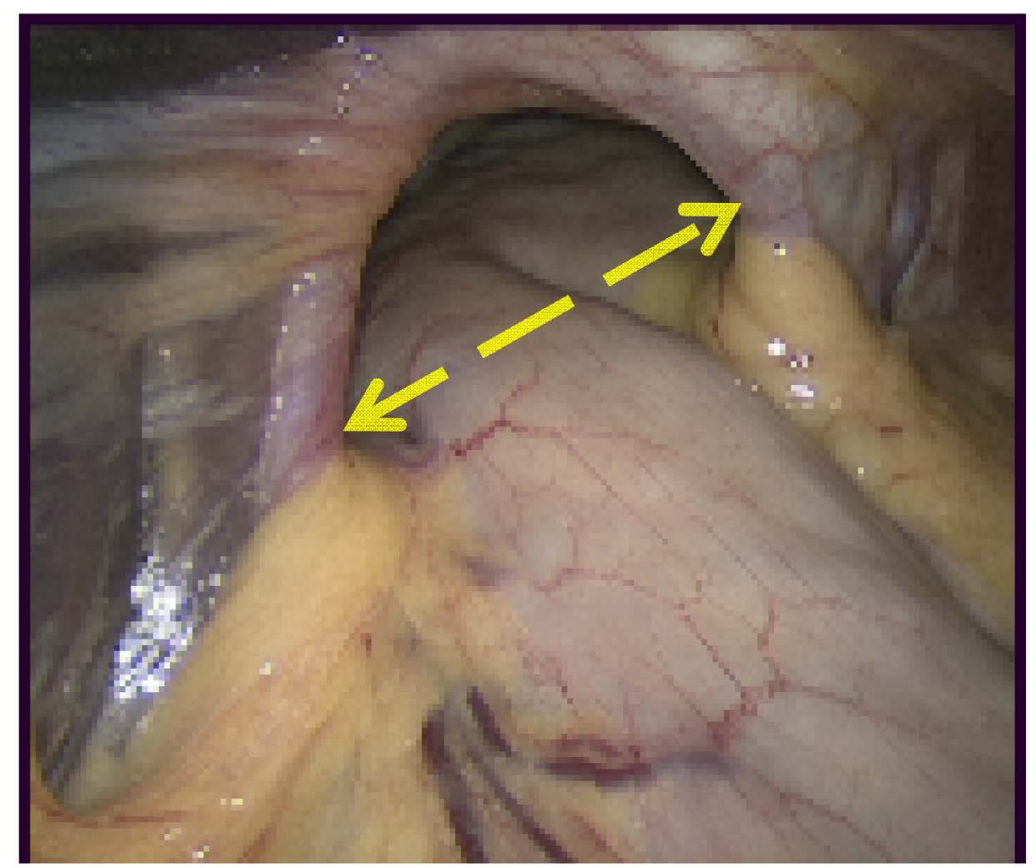

Figure 1. Giant para-oesophageal hernia with large hiatal defect.

\section{Surgical Technique}

The patient is placed in a reverse Trendelenburg Lloyd Davies position. The surgeon is stationed between the patient's legs. The procedure is performed with the placement of 10, 10, 5 and $5 \mathrm{~mm}$ ports in standard positions relevant for anti-reflux surgery (Figure 1 and Figure 2). Nathanson liver retractor is deployed following the induction of pneumoperitoneum to retract segments II and III of the liver.

The GPEH sac is dissected and freed from the mediastinum using the Harmonic scalpel taking care to preserve the peritoneal covering of the crura and the vagi nerves followed by the excision of the hernial sac. Extensive mediastinal dissection around the oesophagus allows 2 - $3 \mathrm{~cm}$ of intra-abdominal oesophagus. The upper short gastric vessels are divided and haemostasis secured. The diaphragmatic crura are juxtaposed posteriorly/ anteriorly (where required) without tension with $6^{1}$ interrupted 0 polyester, braided sutures e.g. Ethibond ${ }^{\circledR}$.

No releasing incisions are made on the diaphragm. We use a $7 \times 6 \mathrm{~cm}$ porcine dermis (Strattice by Acelity, U.S.A), a non cross-linked acellular reconstructive matrix for hiatal reinforcement. A $3 \mathrm{~cm}$, tennis-racquet shaped transverse gap is created from the centre of the shorter border of the $7 \times 6 \mathrm{~cm}$ mesh (Figure 3). The handle-end of the fashioned mesh is introduced from the right towards the left crus that accommodates the oesophagus loosely. The two loose ends of the mesh are kept apart on the left crus preventing full encircleage of the oesophagus and fixed to the diaphragm and crura with 5 interrupted, 0 polyester, braided sutures (Figure 4 ). This is followed by a $360^{\circ}$ loose fundoplication achieved with three interrupted 0 polyester, braided sutures (no bougie used) and then the gastropexy is completed by securing the wrap to the diaphragm, mesh and the right crus with another five interrupted 0 polyester, braided sutures (Figure 5).

\section{Discussion}

Laparoscopic repair of GPEH is a technical challenge and simple crura-plasty is associated with high crural disruption, recurrent herniation (up to 42\%) and return of symptoms [1] [2] [4] [5].

Use of prosthesis reduces tension at the hiatus and thus, the recurrence to approximately $7 \%$ - 10\%, however, non-absorbable mesh carries the risk of localised erosion, infection, stricture and dysphagia [1]-[3].

We advocate the use biological prosthesis that would possibly eliminate these risks but would retain the benefits of a tension free hernia repair in this highly dynamic hiatal area.

Currently, there is dearth of literature on the use of biological prosthesis for laparoscopic repair of GPEH.

${ }^{1}$ Median: number of sutures. 


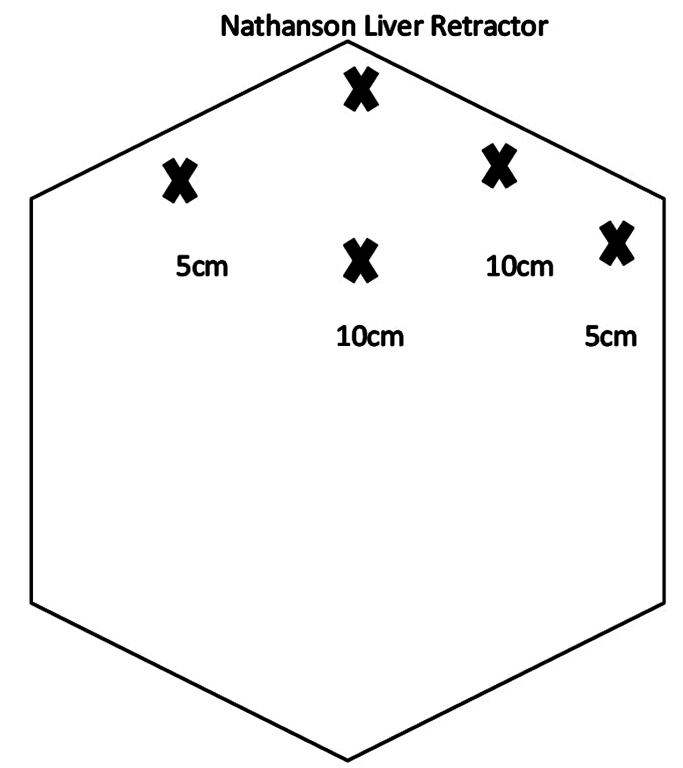

Figure 2. Port placement for antireflux surgery.

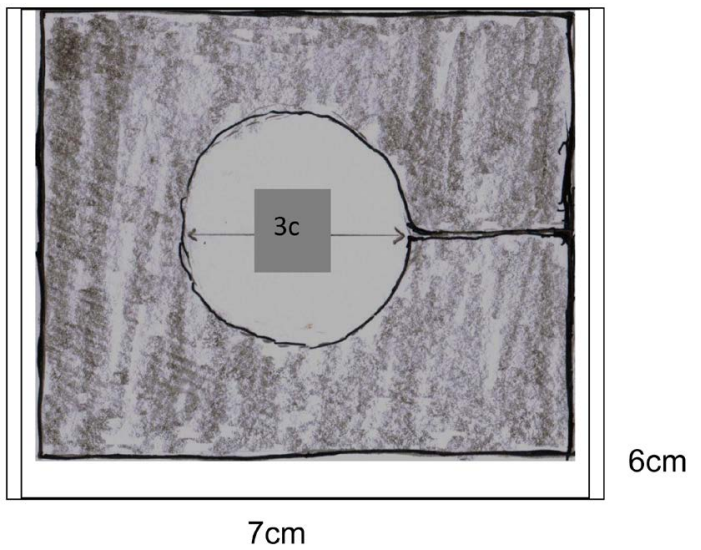

Figure 3. Mesh design.

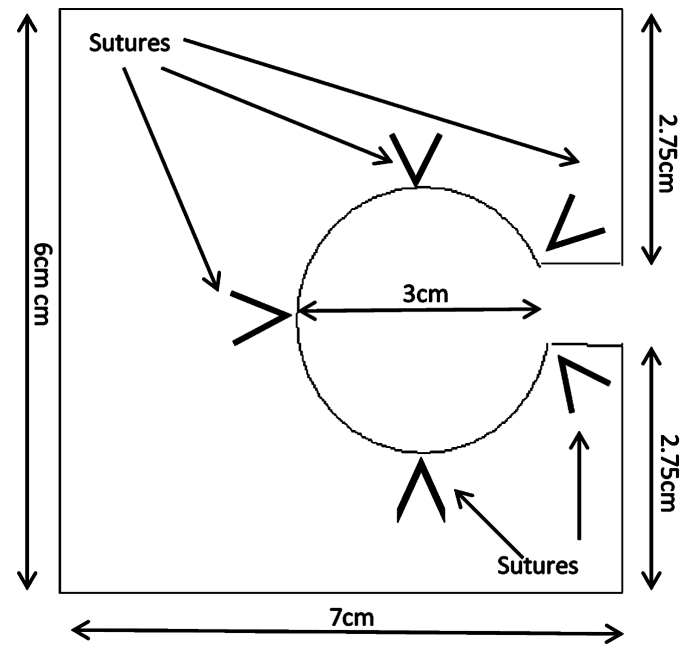

Figure 4. Mesh fixation to the diaphragm. 


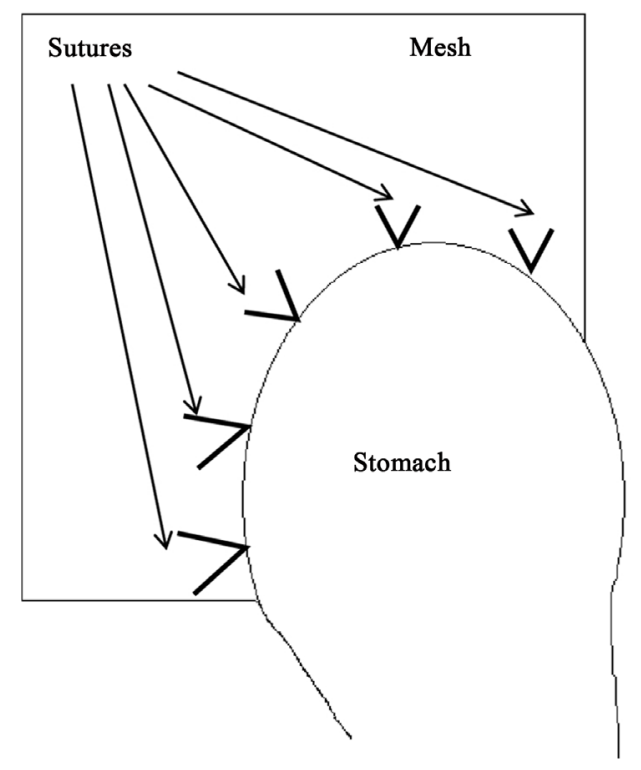

Figure 5. Gastropexy.

\section{Conclusion}

We believe our technique of laparoscopic repair and the use of porcine dermis (non cross-linked) for hiatal reconstruction for patients with GPEH is a safe technique that reduces recurrence and improves quality of life with acceptable morbidity. Further research is required in the use of biological prosthesis for laparoscopic repair of GPEH. We are currently preparing a manuscript reporting our centre's five-year data for over a hundred patients.

\section{Disclosure of Conflicts of Interest and Sources of Financial Support}

There is no conflict of interest or any financial support received for the procedure performed at the William Harvey Hospital, Kent, UK.

Short video of our technique of laparoscopic repair of giant paraoesophageal hernia with biological prosthesis was presented at the $19^{\text {th }}$ International Congress of EAES, Torino, Italy (15-18 June 2011).

\section{References}

[1] Wassenaar, E.B., Mier, F., Sinan, H., Petersen, R.P., Martin, A.V., Pellegrini, C.A. and Oelschlager, B.K. (2011) The Safety of Biologic Mesh for Laparoscopic Repair of Large, Complicated Hiatal Hernia. Surgical Endoscopy, 26, 13901396. http://dx.doi.org/10.1007/s00464-011-2045-y

[2] Luketich, J.D., Nason, K.S., Christie, N.A., Pennathur, A., Jobe, B.A., Landreneau, R.J. and Schuchert, M.J. (2010) Outcomes after a Decade of Laparoscopic Giant Paraesophageal Hernia Repair. Journal of Thoracic and Cardiovascular Surgery, 139, 395-404. http://dx.doi.org/10.1016/j.jtcvs.2009.10.005

[3] Frantzides, C.T., Carlson, M.A., Loizides, S., Papafili, A., Luu, M., Roberts, J., Zeni, T. and Frantzides, A. (2010) Hiatal Hernia Repair with Mesh: A Survey of SAGES Members. Surgical Endoscopy, 24, 1017-1024. http://dx.doi.org/10.1007/s00464-009-0718-6

[4] Pierre, A.F., Luketich, J.D., Fernando, H.C., Christie, N.A., Buenaventura, P.O., Litle, V.R. and Schauer, P.R. (2002) Results of Laparoscopic Repair of Giant Paraesophageal Hernias: 200 Consecutive Patients. Annals of Thoracic Surgery, 74, 1909-1915. http://dx.doi.org/10.1016/S0003-4975(02)04088-2

[5] Oelschlager, B.K., Pellegrini, C.A., Hunter, J.G., Brunt, M.L., Soper, N.J., Sheppard, B.C., Polissar, N.L., Neradilek, M.B., Mitsumori, L.M., Rohrmann, C.A. and Swanstrom, L.L. (2011) Biologic Prosthesis to Prevent Recurrence after Laparoscopic Paraesophageal Hernia Repair: Long-Term Follow-Up from a Multicenter, Prospective, Randomized Trial. Journal of the American College of Surgeons, 213, 461-468. http://dx.doi.org/10.1016/j.jamcollsurg.2011.05.017

[6] Khanna, A. and Finch, G. (2011) Paraoesophageal Herniation: A Review. The Surgeon, 9, 104-111. http://dx.doi.org/10.1016/j.surge.2010.10.010 